\title{
Biological and Phytochemical Investigations on Caesalpinia benthamiana, a Plant Traditionally Used as Antimalarial in Guinea
}

\author{
Jean Loua, ${ }^{1}$ Mohamed Sahar Traore, ${ }^{1,2}$ Aissata Camara, ${ }^{1,2}$ Mamadou Aliou Balde,,2 \\ Louis Maes, ${ }^{3}$ Luc Pieters, ${ }^{4}$ and Aliou Mamadou Balde ${ }^{1,2}$ \\ ${ }^{1}$ Research and Valorization Center on Medicinal Plants, Dubreka, Guinea \\ ${ }^{2}$ Department of Pharmacy, University Gamal Abdel Nasser of Conakry, Conakry, Guinea \\ ${ }^{3}$ Laboratory of Microbiology, Parasitology and Hygiene (LMPH), Faculty of Pharmaceutical, Biomedical and Veterinary Sciences, \\ University of Antwerp, Universiteitsplein 1, 2610 Antwerp, Belgium \\ ${ }^{4}$ Natural Products \& Food Research and Analysis (NatuRA), Department of Pharmaceutical Sciences, University of Antwerp, \\ Universiteitsplein 1, 2610 Antwerp, Belgium
}

Correspondence should be addressed to Aliou Mamadou Balde; bmaliou2002@yahoo.fr

Received 21 February 2017; Revised 7 June 2017; Accepted 25 July 2017; Published 10 September 2017

Academic Editor: Pierre Champy

Copyright (C) 2017 Jean Loua et al. This is an open access article distributed under the Creative Commons Attribution License, which permits unrestricted use, distribution, and reproduction in any medium, provided the original work is properly cited.

\begin{abstract}
Caesalpinia benthamiana is widely used as antimalarial in Guinean traditional medicine. Leaf extracts of the plant were tested for their in vitro antiprotozoal activity against Trypanosoma brucei brucei and T. cruzi and the chloroquine-sensitive Ghana strain of Plasmodium falciparum along with their cytotoxicity on MRC-5 cells. The methanolic extract showed the strongest antiprotozoal activity against $P$. falciparum $\left(\mathrm{IC}_{50} 4 \mu \mathrm{g} / \mathrm{ml}\right.$ ), a good activity against $T$. brucei $\left(\mathrm{IC}_{50} 13 \mu \mathrm{g} / \mathrm{ml}\right)$, and a moderate activity against $T$. cruzi $\left(\mathrm{IC}_{50} 31 \mu \mathrm{g} / \mathrm{ml}\right.$ ) along with an $\mathrm{IC}_{50}$ on human MRC-5 cells of $32 \mu \mathrm{g} / \mathrm{ml}$. Bioassay-guided fractionation from the methanolic extract led to antiplasmodially active subfractions. A prospective, placebo-controlled ethnotherapeutic trial assessed the antimalarial effectiveness and tolerability of $C$. benthamiana syrup administered orally to children with uncomplicated malaria as compared with chloroquine syrup. Phytochemical screening of the leaf extracts indicated the presence of flavonoids, terpenoids, tannins, saponins, and iridoids.
\end{abstract}

\section{Introduction}

Malaria is the most important parasitic disease of human beings. It is transmitted in more than 100 countries inhabited by roughly 3 billion people [1]. Approximately 3.2 billion people, almost half the world's population, are exposed to malaria risk [2]. According to the most recent statistics of the World Health Organization's World Malaria Report 2015, an estimated 214 million new cases of malaria and 438,000 deaths had been recorded worldwide [2]. More than $85 \%$ of malaria cases and $90 \%$ of malaria deaths occur in SubSaharan Africa, mainly in young children (i.e., those younger than 5 years old) [1].

A dramatic revival of malaria is ongoing due to the increasing resistance of vectors to insecticides and to the progressive resistance of the parasite, mainly Plasmodium falciparum, to drugs [3, 4]. Moreover, resistance to artemisinins has now been detected in five countries in the Greater Mekong subregion: Cambodia, Laos, Myanmar, Thailand, and Vietnam [2].

Guinea is highly endemic for malaria, with a prevalence in children younger than 5 years old of $44 \%$ in a 2012; Malaria is the main cause of visits to health facilities, accounting for more than $30 \%$ of visits to public health facilities [5]. Due to financial, geographical, and/or cultural obstacles, most Guinean people especially in rural areas are still not accessing the services they need to prevent and treat malaria and affected populations turn towards traditional medicine and medicinal plants to solve their health problems. 
TABLE 1: In vitro antiprotozoal and cytotoxic activity of Caesalpinia benthamiana fractions $(\mathrm{Mb})$.

\begin{tabular}{lcccc}
\hline \multicolumn{4}{c}{ Antiprotozoal activity, $\mathrm{IC}_{50}(\mu \mathrm{g} / \mathrm{ml})$} & MRC-5 \\
Fractions & P. falciparum & T. brucei & T. brucei & $\mathrm{IC}_{50}(\mu \mathrm{g} / \mathrm{ml})$ \\
\hline $\mathrm{Mb1}$ & 4 & 31 & 13 & 32 \\
$\mathrm{Mb} 2$ & $>64$ & $>64$ & 32 & $>64$ \\
$\mathrm{Mb3}$ & 16 & 34 & $>64$ & 33 \\
Chloroquine & $0.047 \mu \mathrm{M}$ & & & \\
Suramin & & & $0.035 \mu \mathrm{M}$ & \\
Benznidazole & & $2.0 \mu \mathrm{M}$ & & \\
\hline
\end{tabular}

In the search for new therapeutic agents against malaria from the Guinean flora, a series of ethnobotanical investigations were realized by the Guinean "Centre de Recherche et de Valorisation des Plantes Médicinales (CRVPM) de Dubréka." Among the collected plants Caesalpinia benthamiana (Baill.) Herend. \& Zarucchi (Synonym: Mezoneuron benthamianum Baill.) (Fabaceae) was selected for an ethnopharmacological investigation.

C. benthamiana is well-known in Guinean traditional medicine for the treatment of various illness including malaria [6] and preliminary biological studies showed a remarkable antiplasmodial activity of this plant species with an $\mathrm{IC}_{50}$ value of $5.8 \mu \mathrm{g} / \mathrm{ml}$ against Plasmodium falciparum [7].

The aim of this study was to determine the in vitro antiprotozoal activity of C. benthamiana extracts (Table 1), to carry out a preliminary phytochemical investigation of the leaves of $C$. benthamiana, and to conduct a prospective, placebo-controlled ethnotherapeutic trial to assess the antimalarial effectiveness and tolerability of a $C$. benthamiana syrup administered orally to children with uncomplicated malaria as compared to chloroquine syrup.

\section{Material and Methods}

2.1. Plant Material. The leafed twigs of $C$. benthamiana were harvested in the prefecture of Dubréka in September 2006. The voucher specimen was authenticated by the Department of Botany of the "Centre de Recherche et de Valorisation des Plantes Médicinales (CRVPM), Dubréka" and deposited in the herbarium of this Center (No. 27HK411). The sample was dried at room temperature and pulverized.

2.2. Ethnotherapeutic Evaluation. The ethnotherapeutic evaluation was made mainly on the basis of the knowledge and recommendations of the traditional healer owning the recipe and within his community where $C$. benthamiana is largely used either for the treatment of malaria and other infectious diseases.

2.3. Study Site and Participants. This ethnotherapeutical trial took place at Dubréka, an area of high malaria transmission in Guinea. The study was conducted between June and July 2007, within the district hospital of Dubréka.
2.4. Entry Criteria. Subjects with a positive thick drop test were included if they fulfilled all the following inclusion criteria:

(1) Age between 5 and 15 years old,

(2) Mono-infection with $P$. falciparum infection,

(3) Parasitaemia $\geq 1000$ asexual parasites/ $\mu \mathrm{l}$,

(4) Haemoglobin $(\mathrm{Hb}) \geq 5 \mathrm{~g} / \mathrm{dl}$,

(5) Availability during the study,

(6) Fever $\geq 37.5^{\circ} \mathrm{C}$ (or history of fever during the past $24 \mathrm{~h})$.

Subjects were excluded if they had any of the following:

(1) A history of allergy to the study drugs,

(2) Having taken an antimalarial drug in the previous $72 \mathrm{~h}$,

(3) Fever due to diseases other than malaria or other known underlying chronic diseases,

(4) Severe illness,

(5) Medications that may interfere with antimalarial drugs,

(6) Presenting any dangerous signs of severe malaria [8].

All parents/guardians were requested to give written consent before entering the study. The aims and procedures of the study were explained to each patient or parent/guardian and his/her understanding was confirmed by interview before written or, in case of illiteracy, thumb-printed consent in the presence of an unbiased witness. This study was approved by the Ethical Committee of the Center.

2.5. Clinical Monitoring. Clinical examination was directed by the research team doctor and targeted the body weight, temperature, palpation, and auscultation.

2.6. Laboratory Procedures. At enrolment, $5 \mathrm{ml}$ of venous blood was drawn to confirm the diagnosis of $P$. falciparum malaria with Giemsa stained thick and thin smears, stored blood on filter paper for further parasite genotyping, and to obtain a complete hemogram (manually), haematocrit (\%), haemoglobin concentration ( $\mathrm{g} / \mathrm{dl})$, and blood glucose $(\mathrm{mmol} / \mathrm{l})$. The smears and filter paper blood samples were also collected from finger pricks on days $0,3,7,14$, and 28 . The smears were read by a laboratory technician experienced in malaria diagnosis. Parasitaemia was calculated based on the number of asexual forms observed in 200 leucocytes and then multiplied by 40 .

2.7. Galenic Formulation. Based on the traditional way of using C. benthamiana, $3000 \mathrm{~g}$ of the leaf powder was extracted by percolating with $2 \times 51$ of ethanol $70^{\circ}$ during $48 \mathrm{~h}$. The resulting extracts were concentrated under reduced pressure at $40^{\circ} \mathrm{C}$ to yield $220 \mathrm{~g}$ of the wimpy crude extract which was mixed with $500 \mathrm{ml}$ of hot water, and then a sufficient quantity of simple syrup was added to get $3330 \mathrm{ml}$ of Caesalpinia syrup.

The chloroquine syrup was purchased at the Central Pharmacy of Guinea (PCG). 
2.8. Treatment Assignment. In order to compare the two regimens, children were divided into two groups assigned to receive either syrup of $C$. benthamiana for group I or chloroquine syrup ( $5 \mathrm{mg} / \mathrm{ml}$ ) for group II. Group I received $2 \times 15 \mathrm{ml}$ (morning and evening) per day of $C$. benthamiana syrup orally from day 1 (D1) to day 5 (D5) $(150 \mathrm{ml})$. The second group received $10 \mathrm{mg} / \mathrm{kg}$ of chloroquine at D1 and $\mathrm{D} 2$, then $5 \mathrm{mg} / \mathrm{kg}$ at D3 [9]. Children were observed for $30 \mathrm{~min}$ after each drug administration. Treatments were readministered if the child vomited.

Follow-Up. Subjects were followed up on days 0, 3, 7, 14, and 28 for clinical and laboratory assessments described above.

2.9. Phytochemical Investigation. A portion of the leaf powder was subjected to phytochemical analysis, using standard chemical tests. Phytochemical screening of the crude extract was carried out employing standard methods and tests [10].

For the preliminary phytochemical analysis, $100 \mathrm{~g}$ of powdered leaves of $C$. benthamiana was macerated with $500 \mathrm{ml}$ of EtOH $70^{\circ}(48 \mathrm{~h})$. The extract was concentrated under vacuum and dried. The dried extract was tested for the presence of different phytoconstituents, namely, terpenoids, alkaloids, coumarins, tannins, anthraquinones, flavonoids, anthocyanins, saponins, and iridoids, by TLC using precoated silica gel plates (Merck) and common coloration and precipitation reactions $[11,12]$.

2.10. Fractionation. The active extract and its fractions were consecutively submitted to a bioassay-guided fractionation by column chromatography on silica gel 60-200 mesh (Merck) with dichloromethane/ethyl acetate as eluent, with a gradient of increasing polarity. Analytical TLC was performed on precoated silica gel $60 \mathrm{~F}_{254}$ plates (Merck; $0.25 \mathrm{~mm}$ ) with the following mobile phases: dichloromethane/toluene $7: 3$ and dichloromethane $100 \%$.

2.11. Preparation of the Extracts. Powdered leafed twigs of $C$. benthamiana $(50 \mathrm{~g})$ were macerated with $500 \mathrm{~mL}$ of either methanol, distillated water, or $\mathrm{CH}_{2} \mathrm{Cl}_{2}$ for $72 \mathrm{~h}$ to give three extracts which were evaporated to dryness in vacuo at $40^{\circ} \mathrm{C}$ to give Mb1 (12.46 g); Mb2 (6.68 g); Mb3 (5.15 g), respectively.

2.12. In Vitro Antiprotozoal Screening. The extracts were tested for their antiprotozoal activity and cytotoxicity (MRC5 cells) according to a previously described method [13]. The antiplasmodial activity of extracts and fractions was evaluated in vitro against a chloroquine-sensitive strain of Plasmodium falciparum (3D7) using a modified procedure according to Makler et al. [14] (lactate dehydrogenase assay).

Positive controls were tamoxifen and suramin (SigmaAldrich) for MRC-5 and T. brucei, respectively, and benznidazole and chloroquine (WHO-TDR, Geneva, Switzerland) for T. cruzi and P. falciparum, respectively. [7].

2.13. Bioassay-Guided Fractionation. The active extract and fractions were consecutively submitted to bioassay-guided fractionation by column chromatography on silica gel 60-200 mesh (Merck) as indicated above. The fractions were tested against $P$. falciparum and T. cruzi.

2.14. Statistical Analysis. Statistical analyses were performed using Excel, Mann-Whitney test, and SPSS version 20.0.

Significance was set at $p<0.05$.

\section{Results}

\subsection{Biological Activity}

3.1.1. In Vitro Antiprotozoal Activity. The most active antiprotozoal extract was the methanolic extract (Mb1), which showed a pronounced activity against $P$. falciparum $\left(\mathrm{IC}_{50}\right.$ $4 \mu \mathrm{g} / \mathrm{ml})$, a moderate activity against $T$. brucei $\left(\mathrm{IC}_{50} 13 \mu \mathrm{g} / \mathrm{ml}\right)$, and a weak activity against $T$. cruzi $\left(\mathrm{IC}_{50} 31 \mu \mathrm{g} / \mathrm{ml}\right)$; it was cytotoxic on human MRC-5 cells with an $\mathrm{IC}_{50}$ of $32 \mu \mathrm{g} / \mathrm{ml}$. The apolar extract Mb3 was four time less active against $P$. falciparum than $\mathrm{Mb} 1$ while $\mathrm{Mb} 2$ was inactive $\left(\mathrm{IC}_{50}>\right.$ $64 \mu \mathrm{g} / \mathrm{ml}$ ). Indeed, $\mathrm{Mb} 2$ was only active against T. brucei and less cytotoxic $\left(\mathrm{IC}_{50}>64 \mu \mathrm{g} / \mathrm{ml}\right)$ than $\mathrm{Mbl}$ and $\mathrm{Mb} 3\left(\mathrm{IC}_{50} 32\right.$ and $33 \mu \mathrm{g} / \mathrm{ml}$, resp.).

A bioassay-guided fractionation led to 7 subfractions: Mb1.1 to Mb1.7. The subfractions Mb1.1 and Mb1.2 were the most antiplasmodially active with an $\mathrm{IC}_{50}$ of $2 \mu \mathrm{g} / \mathrm{ml}$, each, along with a cytotoxicity $\mathrm{IC}_{50}$ of 29 and $>64 \mu \mathrm{g} / \mathrm{ml}$, respectively. A combination of these two subfractions (Mb1.1m) was refractionated yielding 8 subfractions, Mb1.1m1 to Mb1.1m8. All of these were less active than Mb1.1 or Mb1.2. However, a strong antiplasmodial effect was observed for Mb1.1m4 and $\mathrm{Mbl} .1 \mathrm{~m} 5$ ( $\mathrm{IC}_{50} 4.24$ and $4.00 \mu \mathrm{g} / \mathrm{ml}$, resp.), while a good activity was recorded for $\mathrm{Mb} 1.1 \mathrm{~m} 3$ and $\mathrm{Mb} 1.1 \mathrm{~m} 2\left(\mathrm{IC}_{50}\right.$ 6.49 and $7.18 \mu \mathrm{g} / \mathrm{ml}$, resp.). The other subfractions were moderately active $\left(\mathrm{IC}_{50} 17.42\right.$ to $\left.19.85 \mu \mathrm{g} / \mathrm{ml}\right)$.

On the other hand, Mb1.1, Mb1.2, and Mb1.3 showed the best antitrypanosomal activity against $T$. cruzi $\left(\mathrm{IC}_{50} 8,16\right.$, and $10 \mu \mathrm{g} / \mathrm{ml}$, resp.) and $T$. brucei $\left(\mathrm{IC}_{50} 32,35\right.$, and $33 \mu \mathrm{g} / \mathrm{ml}$, resp.). However, with an $\mathrm{IC}_{50}$ of $29 \mu \mathrm{g} / \mathrm{ml}, \mathrm{Mb1} 1 \mathrm{l}$ was also the most cytotoxic fraction among all the tested subfractions (Figure 2).

\subsection{Ethnotherapeutic Evaluation}

3.2.1. Baseline Characteristics. A total of 219 children were screened and from these 42 patients were enrolled in the study with 21 receiving chloroquine (CQ group) and 21 others receiving the $C$. benthamiana syrup ( $\mathrm{Mb}$ group) (Figure 1 ). The mean parasitaemia of the patients was not significantly different ( $p$ 0.82): 1847,76 $\pm 1629,38$ for the $\mathrm{Mb}$ group (group I) and 1753,95 \pm 1557,99 for the CQ Group (group II). The patient demography and baseline characteristics are summarized in Table 2. It is important to note that most of the patients had consumed a paracetamol-based antipyretic before their enrolment.

3.2.2. Efficacy. A significant parasitic load reduction was noticed from day 0 to day 28 for both $\mathrm{Mb}$ and CQ treatments (Table 3; Figure 3). No significant difference was observed between the two treatment groups on follow-up days 3, 
TABLE 2: Baseline characteristics of enrolled patients on day 0.

\begin{tabular}{lcc}
\hline Patient characteristics & Group I: $\mathrm{Mz}(n=21)$ & Group II: CQ $(n=21)$ \\
\hline Gender: male/female (ratio) & $10 / 11(0.91)$ & $12 / 9(1.33)$ \\
Age groups (\%) & & \\
$5-6$ & $2(9.52 \%)$ & $2(9.52 \%)$ \\
$7-8$ & $1(4.76 \%)$ & $4(19.05 \%)$ \\
$9-10$ & $6(28.57 \%)$ & $4(19.05 \%)$ \\
$11-12$ & $5(23.81 \%)$ & $8(38.09 \%)$ \\
$13-15$ & $7(33.33 \%)$ & $3(14.29 \%)$ \\
Mean of body temperature, ${ }^{\circ} \mathrm{C}\left(\mathrm{maxima}^{3}\right.$ minima) & $36.87(37.7-36.2)$ & $37.01(37.5-36.0)$ \\
Geometric mean Parasitaemia/mm $( \pm \mathrm{SD})$ & $1847,76(1629,38)$ & $1753,95(1557,99)$ \\
Haemoglobin concentration, $\mathrm{mean}(\mathrm{g} / \mathrm{dl})$ & $8.65(12-6)$ & $9.43(14-5)$ \\
Hematocrit $(\%)$ & $35.48(42-26)$ & $33.86(40-26)$ \\
Blood glucose $(\mathrm{mmol} / \mathrm{l})$ & $5.89(7.2-4.3)$ & $5.42(7.2-4.4)$ \\
\hline
\end{tabular}

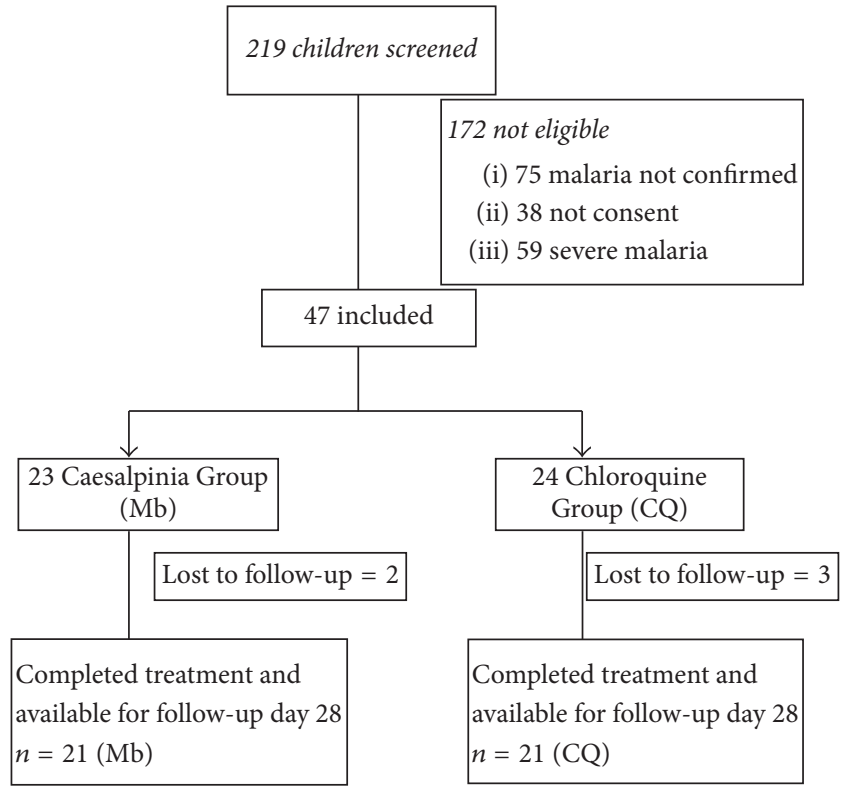

Figure 1: Trial profile

7 , 14, and 28 with $p$ values of $0.96 ; 0.77 ; 0.72$; and 0.79 . However, parasite clearance was observed for one patient at D7, two patients at D14, and four patients for D28 in the C. benthamiana arm and only four patients at D28 in the chloroquine arm.

3.2.3. Tolerance. During the 28-day follow-up period, both treatments with $\mathrm{Mb}$ and CQ were well tolerated with the majority of adverse effects of mild or moderate severity, and consistent with symptoms attributable to malaria. The frequency of individual adverse events was generally similar between the two treatments, although the incidence of posttreatment adverse events (AEs) was slightly higher in patients treated with CQ (Table 3). Among the laboratory parameters, the concentration of mean $\mathrm{Hb}$ fell from $8.65 \mathrm{~g} / \mathrm{dl}(\mathrm{Mb})$ and $9.43 \mathrm{~g} / \mathrm{dl}(\mathrm{CQ})$ on day 0 to $7.78 \mathrm{~g} / \mathrm{dl}(\mathrm{Mb})$ and $8.17 \mathrm{~g} / \mathrm{dl}(\mathrm{CQ})$ on day 7 , before increasing progressively thereafter.

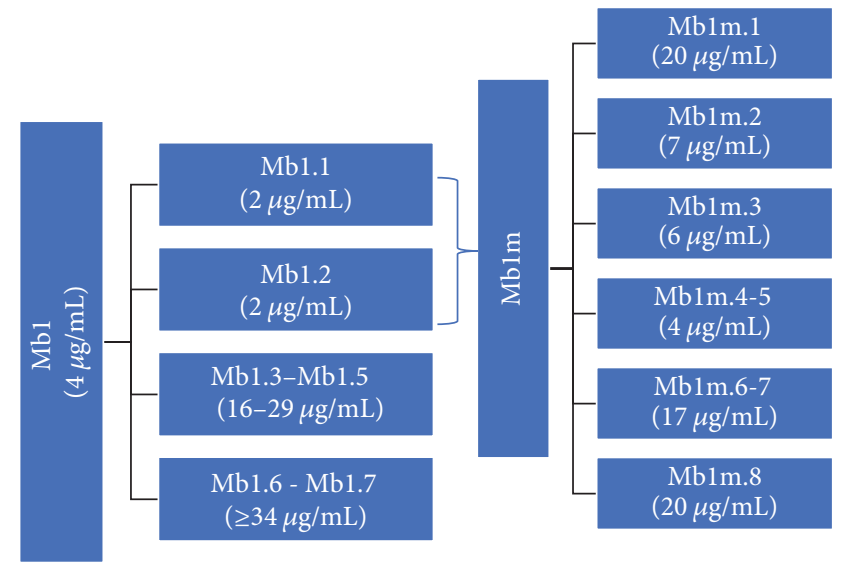

FIGURE 2: Bioassay-guided fractionation: In vitro antimalarial activity of fractions and subfractions of $C$. benthamiana (M. benthamianum, $\mathrm{Mb}$ ).



FIGURE 3: Evolution of parasitaemia during the treatment.

The haematocrit values decreased from D0 to D14 before increasing at D28. The blood glucose value did not change significantly in both treatments.

3.3. Phytochemical Screening. A qualitative investigation on the leaf extract of $C$. benthamiana revealed the presence of 
TABLE 3: Therapeutic responses of patients treated with $\mathrm{Mb}$ and chloroquine syrups from day 3 to day 28 .

\begin{tabular}{|c|c|c|}
\hline Parameters & Group I: $\mathrm{Mb}(n=21)$ & Group II: CQ $(n=21)$ \\
\hline \multicolumn{3}{|c|}{ Body temperature ${ }^{\circ} \mathrm{C}$, mean } \\
\hline Day 3 & $36.75(38.0-36.2)$ & $36.55(37-36)$ \\
\hline Day 7 & $36.8(38.1-36.2)$ & $36.87(37.7-36.5)$ \\
\hline Day 14 & $36.69(37.5-35.9)$ & $36.6(37.7-35.7)$ \\
\hline Day 28 & $36.58(37.4-35.1)$ & $36.82(37.5-36)$ \\
\hline \multicolumn{3}{|c|}{ Geometric mean parasitaemia $/ \mathrm{mm}^{3} \pm \mathrm{SD}$} \\
\hline Day 3 & $823,24 \pm 778$ & $771,81 \pm 584$ \\
\hline Day 7 & $480,00 \pm 451,69$ & $449,14 \pm 448,43$ \\
\hline Day 14 & $359,62 \pm 377,64$ & $432,00 \pm 428,34$ \\
\hline Day 28 & $153,14 \pm 250,20$ & $165,71 \pm 311,87$ \\
\hline \multicolumn{3}{|c|}{ Blood glucose (mmol/l) } \\
\hline Day 7 & $5.5(7.3-4.5)$ & $5.38(7.1-4.1)$ \\
\hline Day 14 & $5.53(6.9-4.3)$ & $5.63(9-4.6)$ \\
\hline Day 28 & $5.34(7.2-4.6)$ & $5.64(7.8-4.2)$ \\
\hline \multicolumn{3}{|c|}{ Hematocrit (\%) } \\
\hline Day 7 & $34.76(40-29)$ & $33.67(40-28)$ \\
\hline Day 14 & $29.81(36-20)$ & $28.95(36-24)$ \\
\hline Day 28 & $31.05(40-26)$ & $31.81(36-26)$ \\
\hline \multicolumn{3}{|c|}{ Haemoglobin concentration, mean g/dl } \\
\hline Day 7 & $7.78(10-6)$ & $8.17(11-6.2)$ \\
\hline Day 14 & $8.95(11.1-6)$ & $8.91(11-7.1)$ \\
\hline Day 28 & $8.95(10.8-6.8)$ & $9.18(12-7)$ \\
\hline
\end{tabular}

flavonoids, terpenoids, tannins, saponins, and iridoids. Based on the intensity of their coloration or precipitation during the screening, it can be assumed that tannins and flavonoids are among the majority constituents of $C$. benthamiana.

\section{Discussion}

Billions of people in developing countries still use traditional medicinal plants to fulfill their primary health care needs $[6$, $15,16]$. In the treatment of malaria, the traditional medicines have been used for thousands of years and have been leading sources of important antimalarial drugs known today $[6,17$, $18]$.

4.1. In Vitro Antiprotozoal Screening. Of the three tested extracts, the aqueous one was less active $\left(\mathrm{IC}_{50}>64 \mu \mathrm{g} / \mathrm{ml}\right)$ against $P$. falciparum. The methanolic extract showed the highest antiplasmodial activity $\left(\mathrm{IC}_{50} 4 \mu \mathrm{g} / \mathrm{ml}\right)$ which was in accordance with that of the methanolic extract $\left(\mathrm{IC}_{50}\right.$ $5.84 \mu \mathrm{g} / \mathrm{ml}$ ) previously described [7]. Paradoxically, the aqueous extract is the only one widely and well used in Guinean traditional medicine, suggesting that the active compounds could be less hydrosoluble. This is in agreement with a recent report on the moderate activity of the hydroethanolic extract ( $\mathrm{IC}_{50} 22.5-32.6 \mu \mathrm{g} / \mathrm{ml}$, depending on the batch) and the pronounced activity of the resulting precipitate $\left(\mathrm{IC}_{50}\right.$ $6.5 \mu \mathrm{g} / \mathrm{ml})[8]$.
Upon consideration of these results, it could be assumed that the antiplasmodial constituents could be a mixture of polar and apolar active compounds. Due to the fact that the methanolic extract was 4 time more active than the dichloromethane extract, along with the decreasing activity observed during the bioassay-guided fractionation of the 2 active subfractions (Mb1.1 and Mb1.2.), the antiplasmodial properties of the leaf extract were most likely related to the presence of semipolar constituents which probably act synergistically.

4.2. Phytochemical Investigations. The phytochemical analysis of the $70 \% \mathrm{EtOH}$ leaf extract of $C$. benthamiana revealed the presence of flavonoids, terpenoids, tannins, saponins, which was in accordance with previous reports [18-22], and iridoids. Since the presence of iridoids in the Fabaceae family is not so usual, further studies are essential to find out their presence in C. benthamiana. However, iridoid glucosides such as javanicosides $A$ and $B$ have been described in the leaves and stem bark of another Fabaceae plant species, Parkia javanica [23]. Based on the intensity of coloration or precipitation, the leaf extract may be rich in tannins and flavonoids. The absence of anthraquinones in our samples contrasted with described previous report by [22]; this is probably due to the different geographical origin of the tested samples.

The presence of mezobenthamic acids $\mathrm{A}$ and $\mathrm{B}$ and neocaesalpin $\mathrm{H}$ (terpenoids), kaempferol and quercetin (flavonoids), resveratrol, gallic acid, and its ethyl ester, $\beta$-sitosterol glucoside, and $13 \beta$-hydroxypheophorbide has recently been described in C. benthamiana [8].

Since the leaf extract contains many different classes of compounds, the antimalarial effect of the extracts could be related to the combined effect of both polar and apolar constituents. Although the tannin-rich fractions of Punica granatum did not inhibit the growth of $P$. falciparum, their presence could enhance the solubility of hydrophobic molecules and drugs [24].

On the other hand, triterpenoid and steroid saponins have been found to be active against several infectious protozoa such as $P$. falciparum [25].

Based on the fact that the $\mathrm{MeOH}$ extract was more active in vitro than aqueous or $\mathrm{CH}_{2} \mathrm{Cl}_{2}$ extracts, and in order to find the active principles, a bioassay-guided fractionation was performed, which led to two subfractions with a significant activity $\left(\mathrm{IC}_{50} 2 \mu \mathrm{g} / \mathrm{ml}\right.$ for each). But when a second fractionation was done from the two-combined active subfractions, the antimalarial effect observed for each of the active fractions decreased as compared with the mother subfraction (Figure 2). This decreasing activity during successive fractionations could be in favor of a synergistic effect of different active constituents. This is supported by the fact that $C$. benthamiana was found to contain gallic acid derivatives which have been described to exert a significant antiplasmodial effect [18, 26-29]. Recently, it was found that the antimalarial compounds belong to several phytochemical classes including flavonoids, pheophorbide and gallic acid derivatives, contributing to the global antiplasmodial activity of the hydroalcoholic extract against P. falciparum [8]. 
4.3. Therapeutical Evaluation. A weak clearance of parasitaemia was evident for both treatments, and the progressive and significant reduction exerted by the $C$. benthamiana preparation on the parasitaemia burden supports the traditional use of the plant in the management of malaria.

The treatment with the Caesalpinia (Mezoneuron) syrup was safe and able to reduce the parasitaemia burden in children of 5-15 years. C. benthamiana appeared to be as efficient as CQ for the treatment of uncomplicated $P$. falciparum malaria (Figure 3). However, the noninferiority of the Mezoneuron syrup as compared with the chloroquine syrup could be related to the chloroquine-resistance recorded in Guinea since 2001 [30].

In addition to the recent publication on this plant species, the therapeutic and antiprotozoal evaluations along with the bioassay-guided fractionation support the traditional use of the leaf of $C$. benthamiana as antimalarial. Since the recent isolation and identification of $13 \beta$-hydroxypheophorbide as the most active compound in the crude extract of the plant among others such as the major compounds ethyl gallate and quercetin [8], the standardization of a phytomedicine is thus facilitated.

Aiming to valorize this plant species, all the above results could help to improve the antiplasmodial activity as well as the traditional pharmaceutical form of C. benthamiana into a standardized phytomedicine which will be submitted to clinical trials in Guinea.

\section{Ethical Approval}

This study was approved by the Ethical Committee of the Center.

\section{Consent}

All parents/guardians were requested to give written consent before entering the study. The aims and procedures of the study were explained to each patient or parent/guardian and his/her understanding was confirmed by an interview before written or, in case of illiteracy, thumb-printed consent in the presence of an unbiased witness.

\section{Conflicts of Interest}

The authors declare that there are no conflicts of interest regarding the publication of this paper.

\section{Acknowledgments}

The authors acknowledge Olivia Jansen, Luc Angenot, and Michel Frederich (Laboratory of Pharmacognosy, Center for Interdisciplinary Research on Medicines (CIRM), University of Liège, CHU B36, 4000 Liège, Belgium) for their keen interest. They also thank all the patients and their parents for participating in this investigation.

\section{References}

[1] N. J. White, S. Pukrittayakamee, and T. T. Hien, "Malaria," The Lancet, vol. 383, no. 9918, pp. 723-735, 2013.
[2] WHO: World Health Organization, "World malaria report, Library Cataloguing-in- Publication Data, ISBN 978924156515 8," 2015.

[3] F. Gardella, S. Assi, F. Simon et al., "Antimalarial drug use in general populations of tropical Africa," Malaria Journal, vol. 7, article no. 124, 2008.

[4] J. Hemingway, R. Shretta, T. N. C. Wells et al., "Tools and Strategies for Malaria Control and Elimination: What Do We Need to Achieve a Grand Convergence in Malaria?" PLoS Biology, vol. 14, no. 3, Article ID e1002380, 2016.

[5] M. M. Plucinski, T. Guilavogui, S. Sidikiba et al., "Effect of the Ebola-virus-disease epidemic on malaria case management in Guinea, 2014: A cross-sectional survey of health facilities," The Lancet Infectious Diseases, vol. 15, no. 9, pp. 1017-1023, 2015.

[6] M. S. Traore, M. A. Baldé, M. S. T. Diallo et al., "Ethnobotanical survey on medicinal plants used by Guinean traditional healers in the treatment of malaria," Journal of Ethnopharmacology, vol. 150, no. 3, pp. 1145-1153, 2013.

[7] M. S. Traore, S. Diane, M. Diallo et al., "In Vitro Antiprotozoal and Cytotoxic Activity of Ethnopharmacologically Selected Guinean Plants," Planta Medica, vol. 80, pp. 1340-1344, 2014.

[8] O. Jansen, A. T. Tchinda, J. Loua et al., "Antiplasmodial activity of Mezoneuron benthamianum leaves and identification of its active constituents," Journal of Ethnopharmacology, vol. 203, pp. 20-26, 2017.

[9] WHO, "Assessment and monitoring of antimalarial drug efficacy for the treatment of uncomplicated falciparum malaria," 2003, http://www.who.int/malaria/publications/atoz/whohtmrbm200350/en/.

[10] WHO, "Fiche modèle OMS d'information à l'usage des prescripteurs: Médicaments utilisés en parasitologie. Deuxième édition," 1997, http://apps.who.int/medicinedocs/fr/d/Jh2923f/.

[11] C. K. Kokate, Practical Pharmacognosy, Vallabh Prakashan, New Delhi, India, 4th edition, 1994.

[12] J. B. Harborne, "A guide to modern techniques of plant analysis," in Phytochemical Methods, pp. 63-89, Chapman and Hall, London, UK, 3rd edition, 1998.

[13] K. Kuypers, P. Cos, E. Ortega-Barria, D. Vanden Berghe, and L. Maes, "Bioassays for some parasitic protozoa, screening concepts and standard in vitro and in vivo laboratory model," in Biological Screening of Plant Constituents, M. P. Gupta, S. S. Handa, and K. Vanish, Eds., pp. 7-18, International Centre for Science and High Technology, Trieste, Italy, 2006.

[14] M. T. Makler, J. M. Ries, J. A. Williams et al., "Parasite lactate dehydrogenase as an assay for Plasmodium falciparum drug sensitivity," The American Journal of Tropical Medicine and Hygiene, vol. 48, no. 6, pp. 739-741, 1993.

[15] M. M. Iwu, Handbook of African Medicinal Plants, CRC Press, Boca Raton, Fla, USA, 2nd edition, 2014.

[16] C. Tringali, Bioactive Compounds from Natural Sources: Isolation, Characterization and Biological Properties, CRC Press, USA and Canada, 2nd edition, 2003.

[17] H. Ginsburg and E. Deharo, "A call for using natural compounds in the development of new antimalarial treatments-an introduction," Malaria Journal, vol. 10, article S1, supplement 1, 2011.

[18] A. B. Oluwatoyin and A. C. Geoffrey, "Gallic acid derivatives from Caesalpinia benthamianum Leaves," Pharmaceutical Biology, vol. 38, pp. 284-286, 2000.

[19] O. F. Scott, A. Osho, and O. Atolani, "In vitro anticandidal and antioxidant potential of Caesalpinia benthamianum," Journal of Acute Disease, pp. 120-125, 2012. 
[20] F. Scott O and A. Osho, "Comparison of antimicrobial effects of Caesalpinia benthamianum, Heliotropium indicum and Flabellaria paniculata on Candida species," Journal of Microbiology Research, vol. 2, no. 1, pp. 18-23, 2012.

[21] R. A. Dickson, P. J. Houghton, and P. J. Hylands, "Antibacterial and antioxidant cassane diterpenoids from Caesalpinia benthamiana," Phytochemistry, vol. 68, no. 10, pp. 1436-1441, 2007.

[22] A. Osho, "Ethnopharmacological Properties of Ceasalpinia benthamiana - A Mini Review," British Microbiology Research Journal, vol. 4, no. 2, pp. 206-213, 2014.

[23] B. Dinda, B. Chandra Mohanta, S. Debnath et al., "Iridoid glucosides from leaves and stem barks of Parkia javanica," Journal of Asian Natural Products Research, vol. 11, no. 3, pp. 229-235, 2009.

[24] J. K. Jackson and Letchford. K., "Epigallocatechin Gallate or Tannic Acid-Based Formulations," Journal of Pharmaceutical Sciences, vol. 105, pp. 3143-3152, 2016.

[25] F. Delmas, C. Di Giorgio, R. Elias et al., "Antileishmanial activity of three saponins isolated from ivy, $\alpha$-hederin, $\beta$-hederin and hederacolchiside $\mathrm{Al}$, as compared to their action on mammalian cells cultured in vitro," Planta Medica, vol. 66, no. 4, pp. 343-347, 2000.

[26] N. Fabre, E. Deharo, H. Le, C. Girardi, A. Valentin, and G. Valérie Jullian, "LC-ESI-MS/MS analysis of Quassia amara leaves tea. Is antiplasmodial activity of the tea is due to quassinoids?” Planta Medica, vol. 78, no. 11, 2012.

[27] F. Horgen, D. Madulid, C. Angerhofer, J. Pezzuto, D. Soejarto, and N. Farnsworth, "Isolation of gallic acid esters as antiplasmodial constituents of Swintonia foxworthyi (Anacardiaceae)," Phytomedicine, vol. 4, no. 4, pp. 353-356, 1997.

[28] O. A. Binutu and G. A. Cordell, "Gallic acid derivatives from Mezoneuron benthamianum leaves," Pharmaceutical Biology, vol. 38, no. 4, pp. 284-286, 2000.

[29] A. Zamblé, F. Martin-Nizard, S. Sahpaz et al., "Vasoactivity, antioxidant and aphrodisiac properties of Caesalpinia benthamiana roots," Journal of Ethnopharmacology, vol. 116, no. 1, pp. 112-119, 2008.

[30] MSHP (Ministère de la Santé et de l'Hygiène Publique) and PNLP (Programme National de Lutte Contre le Paludisme), "Protocole de prise en charge du Paludisme," 2008. 


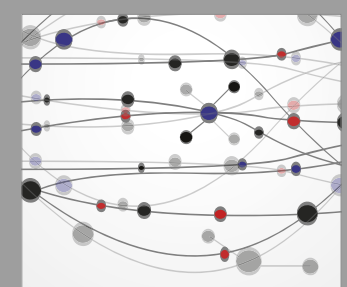

The Scientific World Journal
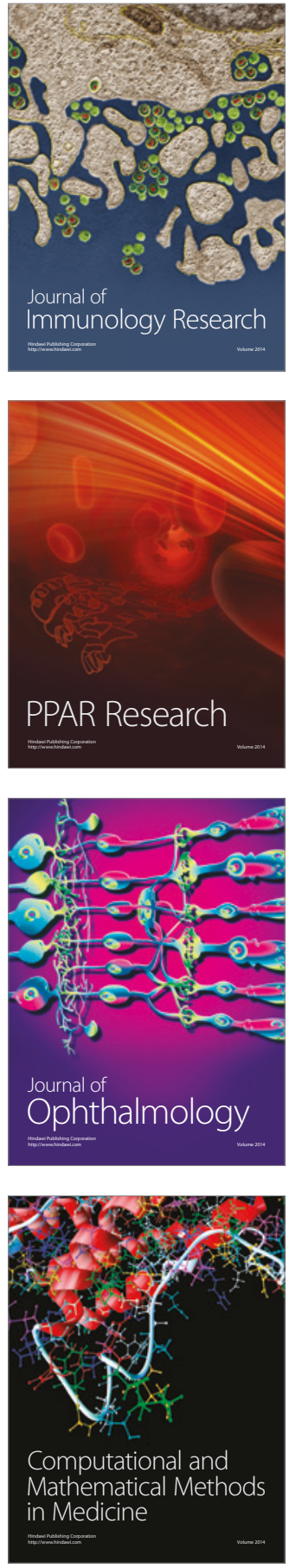



Gastroenterology Research and Practice


\section{Hindawi}

Submit your manuscripts at

https://www.hindawi.com

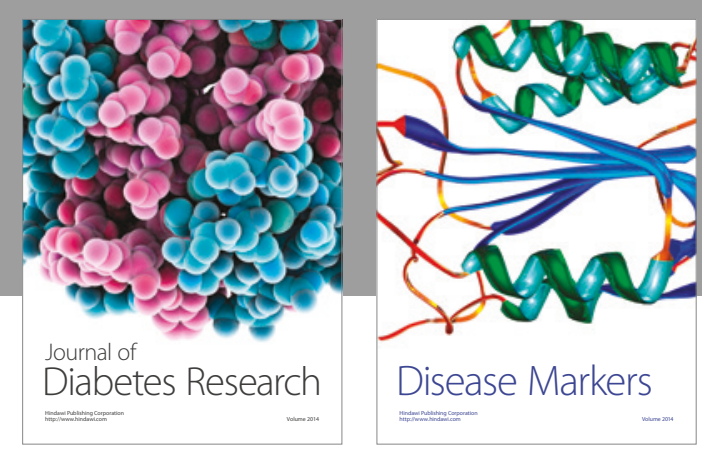

Disease Markers
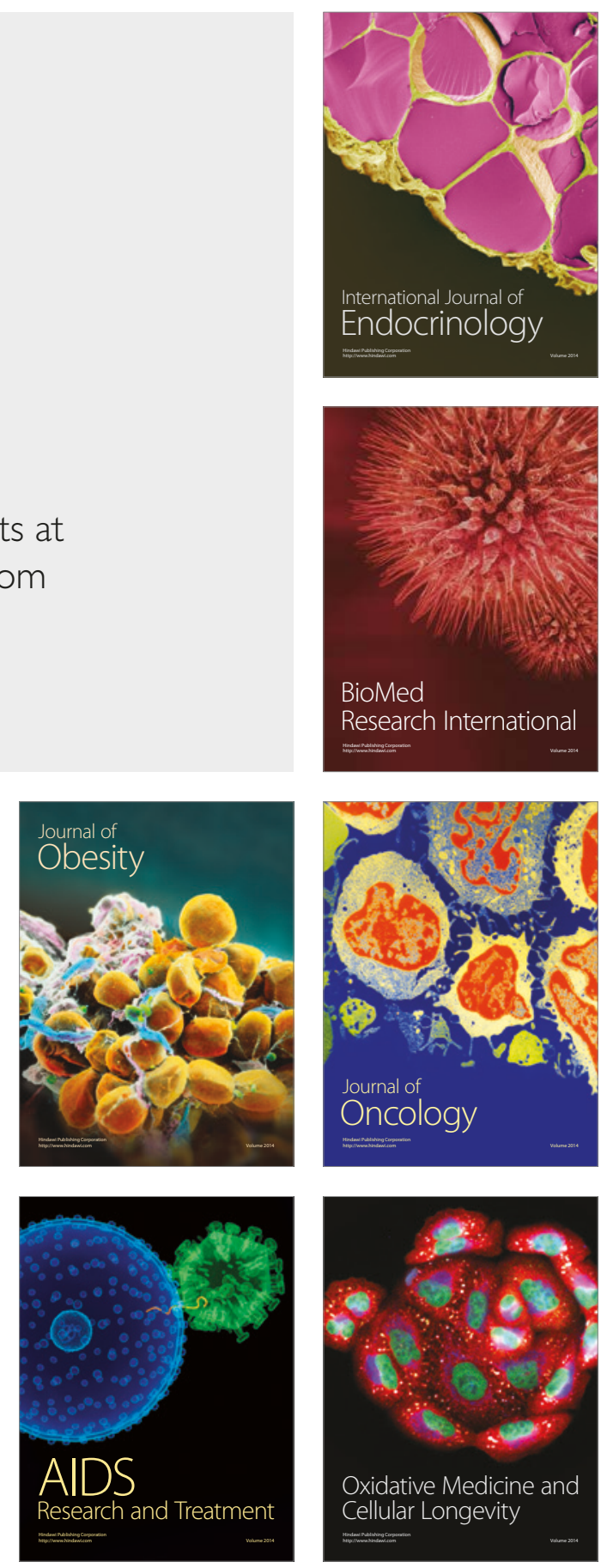